\title{
Stability of vitamin D3 and vitamin D2 in oil, fish and mushrooms after household
} cooking

\author{
Ložnjak, Petra; Jakobsen, Jette
}

Published in:

Food Chemistry

Link to article, DOI:

10.1016/j.foodchem.2018.01.182

Publication date:

2018

Document Version

Peer reviewed version

Link back to DTU Orbit

Citation (APA):

Ložnjak, P., \& Jakobsen, J. (2018). Stability of vitamin $D_{3}$ and vitamin $D_{2}$ in oil, fish and mushrooms after household cooking. Food Chemistry, 254, 144-149. https.//doi.org/10.1046/j.foodchem.2018.01.182

\section{General rights}

Copyright and moral rights for the publications made accessible in the public portal are retained by the authors and/or other copyright owners and it is a condition of accessing publications that users recognise and abide by the legal requirements associated with these rights.

- Users may download and print one copy of any publication from the public portal for the purpose of private study or research.

- You may not further distribute the material or use it for any profit-making activity or commercial gain

- You may freely distribute the URL identifying the publication in the public portal

If you believe that this document breaches copyright please contact us providing details, and we will remove access to the work immediately and investigate your claim. 


\section{Accepted Manuscript}

Stability of vitamin $\mathrm{D}_{3}$ and vitamin $\mathrm{D}_{2}$ in oil, fish and mushrooms after household cooking

Petra Ložnjak, Jette Jakobsen

PII: S0308-8146(18)30206-1

DOI: https://doi.org/10.1016/j.foodchem.2018.01.182

Reference: FOCH 22371

To appear in:

Food Chemistry

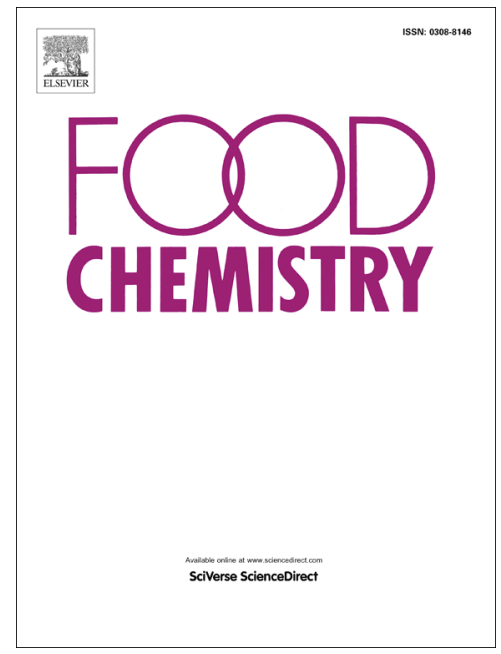

Received Date:

10 July 2017

Revised Date:

12 December 2017

Accepted Date:

30 January 2018

Please cite this article as: Ložnjak, P., Jakobsen, J., Stability of vitamin $\mathrm{D}_{3}$ and vitamin $\mathrm{D}_{2}$ in oil, fish and mushrooms after household cooking, Food Chemistry (2018), doi: https://doi.org/10.1016/j.foodchem.2018.01.182

This is a PDF file of an unedited manuscript that has been accepted for publication. As a service to our customers we are providing this early version of the manuscript. The manuscript will undergo copyediting, typesetting, and review of the resulting proof before it is published in its final form. Please note that during the production process errors may be discovered which could affect the content, and all legal disclaimers that apply to the journal pertain. 


\section{Title:}

Stability of vitamin $\mathrm{D}_{3}$ and vitamin $\mathrm{D}_{2}$ in oil, fish and mushrooms after household cooking

\section{Authors:}

Petra Ložnjak ${ }^{*}$ and Jette Jakobsen

Research Group for Bioactives - Analysis and Application, National Food Institute, Technical University of Denmark, Kemitorvet, DK-2800 Kgs. Lyngby, Denmark. E-mail: jeja@food.dtu.dk

*Corresponding author: Petra Ložnjak, Research Group for Bioactives - Analysis and Application, National Food Institute, Technical University of Denmark, Kemitorvet, DK-2800 Kgs. Lyngby, Denmark, Telephone: + 45 93518869, E-mail: petlon@food.dtu.dk 


\section{Abstract}

Information on the retention of vitamin D in food following household cooking is scarce. So far the retention of its metabolites vitamin $D_{3}$, vitamin $D_{2}$, and 25-hydroxyvitamin $D_{3}$ has shown that the type of food and the cooking method are the essential determinants, and there is no significant difference between the metabolites. We investigated the retention of vitamin $D_{3}$ and vitamin $D_{2}$ in sunflower oil, vitamin $D_{3}$ in rainbow trout, and vitamin $D_{2}$ in button mushrooms. The investigated cooking methods were boiling at different $\mathrm{pH}$, steam cooking, microwave cooking, pan-frying, and oven baking.

There was no difference between the retention of vitamin $D_{3}$ and vitamin $D_{2}$ added to sunflower oil, which ranged from 70-99\%. In rainbow trout, the retention of vitamin $\mathrm{D}_{3}$ at 85 $87 \%$ was not significantly lower than $100 \%(\mathrm{p} \leq 0.05)$. However, the retention of vitamin $\mathrm{D}_{2}$ in mushrooms at $62-88 \%$ was significantly different from $100 \%(\mathrm{p} \leq 0.05)$.

\section{Keywords}

Vitamin D; model system; fish; mushrooms; household cooking; retention 


\section{Introduction}

Vitamin D is a group of fat-soluble sterols that is present in several forms. The two major forms, which differ in their side chain, are cholecalciferol (vitamin $\mathrm{D}_{3}$ ), which is found mainly in foodstuffs of animal origin, and ergocalciferol (vitamin $\mathrm{D}_{2}$ ), which is found in certain fungi such as wild mushrooms.

Figure 1 Structure of cholecalciferol (vitamin $\mathrm{D}_{3}$ ) and ergocalciferol (vitamin $\mathrm{D}_{2}$ )

Except from dietary intake, cholecalciferol can be synthesized in skin cells during exposure to sunlight $(290-315 \mathrm{~nm})$. Sunlight stimulates the conversion of 7 dehydrocholesterol (provitamin $\mathrm{D}_{3}$ ), which naturally occurs in the body, to previtamin $\mathrm{D}_{3}$, which thermally isomerizes into vitamin $\mathrm{D}_{3}$ at body temperature (Wacker \& Holick, 2013). Exposure to UV light also converts ergosterol (provitamin $\mathrm{D}_{2}$ ), present in mushrooms or other fungi, to previtamin $\mathrm{D}_{2}$, which then thermally isomerizes to vitamin $\mathrm{D}_{2}$ (Keegan et al., 2013). Ergocalciferol and cholecalciferol are biologically inert compounds; it is their metabolites that have biological activity. Vitamin D is converted, mainly in the liver, to 25-hydroxyvitamin D, which is further hydroxylated in the kidneys to the metabolically active form 1,25dihydroxyvitamin D (Bikle, 2014). Individuals living at latitudes above $35^{\circ} \mathrm{N}$ or in airpolluted environments produce less vitamin $\mathrm{D}_{3}$ because the winter sunlight lacks UVB and pollution reduces the amount of UVB that reaches the earth's surface. In these conditions, the human body is incapable of supporting the production of vitamin $\mathrm{D}_{3}$ (Webb, 2006). The Institute of Medicine (IOM) recommends $50 \mathrm{nmol} / \mathrm{L}$ as a level of 25 -hydroxyvitamin $\mathrm{D}$ that would be sufficient for skeletal health benefits for all persons (Institute of Medicine, 2011). Previous population-based studies from around the world have reported a prevalence of deficiency $(<50 \mathrm{nmol} / \mathrm{L})$ to be approximately $25 \%$ of the population in Canada, $22-36 \%$ in the USA, 45-52\% in New Zealand, 47-65\% in Korea, and 31\% in Australia (Daly et al., 2012), 
whereas it varies a lot in Europe, with yearly average prevalence of $40 \%$ for European countries (Cashman et al., 2016). Therefore, vitamin D deficiency represents a global public health problem and dietary intake has become increasingly important.

The recommended daily allowance (RDA) is 400-600 IU vitamin D, which is equivalent to 10-15 $\mu \mathrm{g}$ vitamin D/day (Institute of Medicine, 2011; Nordic Nutrient Recommendations, 2014). Vitamin $\mathrm{D}_{3}$ and its metabolites are mostly present in foods of animal origin such as meat, offal, dairy products, eggs, and fish. Fish and fish products are regarded as the major dietary source of vitamin $\mathrm{D}_{3}$, especially salmonids such as salmon (Salmo salar) and rainbow trout (Oncorhynchus mykiss) (Jakobsen and Smith, 2017). Vitamin $\mathrm{D}_{2}$ and its metabolites are present in high amounts in wild mushrooms, whereas their content in foods of animal origin is extremely low. Cultivated button mushrooms (Agaricus bisporus) exposed to UVB during production or after packaging have a high content of vitamin D2 (Keegan et al., 2013; Koyyalamudi et al,, 2009; Kristensen et al., 2012). The UVB exposure process has been approved in the European Union (EU) under the novel food Regulation (EC) No. 258/97 for production and sale of Agaricus bisporus with a content of vitamin $\mathrm{D}_{2} \leq 10$ $\mu \mathrm{g} / 100 \mathrm{~g}$ fresh weight in the EU-market (O'Mahony, 2016, 2017), which makes it possible for vitamin-D-enriched mushrooms to become one of the major dietary sources of vitamin $\mathrm{D}_{2}$.

The information in food composition databases primarily represents the content of vitamin $\mathrm{D}$ in raw food, and the retention of vitamin D is usually estimated to be $100 \%$ in all foods (Pedersen et al., 2015; USDA, 2007; USDA, 2016). However, the investigation of bread, eggs, and margarine prepared by different cooking methods, in general, showed that retention was significantly different from $100 \%$, but there was no difference in retention between the vitamin $\mathrm{D}$ metabolites vitamin $\mathrm{D}_{3}$, vitamin $\mathrm{D}_{2}$, and 25 -hydroxyvitamin $\mathrm{D}_{3}$ (Jakobsen \& Knuthsen, 2014). 
We investigated the retention of vitamin D metabolites in food during cooking methods usually performed in households, such as boiling, frying, and baking, as well as whether the addition of lemon juice affected the retention of vitamin D. Sunflower oil was used as a matrix in which the recovery of vitamin $D_{3}$ and vitamin $D_{2}$ was tested concurrently in the same food matrix, and farmed rainbow trout (Oncorhynchus mykiss) and UVB-exposed button mushrooms (Agaricus bisporus) represented dietary sources of vitamin $\mathrm{D}_{3}$ and vitamin $\mathrm{D}_{2}$, respectively.

\section{Materials and methods}

\subsection{Samples}

\subsubsection{Sunflower oil}

A mixed standard of cholecalciferol (Cholecalciferol C9774, Sigma-Aldrich, Denmark A/S) and ergocalciferol (Ergocalciferol E1007, Sigma-Aldrich, Denmark A/S) was prepared in nheptane (LiChrosolv 104390, Merck Millipore, Germany) to a concentration of $2 \mu \mathrm{g} / \mathrm{mL}$ of each vitamer. To prepare each sample, $5 \mathrm{~g}$ of sunflower oil (Ollineo, Netto, Denmark) was spiked with $375 \mu \mathrm{L}$ of the standard mixture, followed by vortexing, to achieve a concentration of $150 \mathrm{ng}$ vitamer/g of sunflower oil. In total, 8 groups (3 samples per group) were prepared. One group of samples was untreated and served as a control of the vitamin D content in raw button mushrooms. The other groups were treated by different cooking methods, as shown in

Table 1. The table with the experimental design is shown in the supplementary online material (SOM, Section S1, Table S1).

\subsubsection{Rainbow trout}

Four farmed rainbow trout fish (Musholm A/S, Reers $\varnothing$, Denmark) within the weight range of 1.5-2.9 kg were used. From each of the fish, 6 steaks were prepared. Each steak was separated along the spine (right and left looking from the head), and the skin and bones were removed. 
The weight of each of the fish fillets was approximately $100 \mathrm{~g}$. Fillets from the left half were used for the analysis of the raw parts, whereas the counterpart on the right half was heat treated. Photos of the setup and a more detailed description can be found in the supplementary online material (SOM, Section S2, Fig. S2).

\subsubsection{Mushrooms}

24 packages of $250 \mathrm{~g}$ fresh button mushrooms (Agaricus bisporus) each (Egehøj Champignon A/S, Veflinge, Denmark), were transported to National Food Institute, Technical University of Denmark and immediately exposed to a UVB-dose similar to 2 SED from a UVB-lamp specifically developed for optimal vitamin D production in dairy cows (Jakobsen et al., 2015). The irradiation on the mushrooms was measured at $312 \mathrm{~nm}$ using a handheld ILT 1400-BL photometer equipped with a SEL005/TLS312/TD detector (International Light Technologies, Peabody, MA). The irradiance varied from 840 to $1200 \mu \mathrm{W} / \mathrm{cm}^{2}$ (see SOM, Section S3, Fig. S3). The UVB-exposure was performed in four batches with 6 packages in each batch. After exposure, the mushrooms were cleaned and the stalk was cut off. One batch $(n=6)$ was used to analyze the content of vitamin $\mathrm{D}_{2}$ in raw mushrooms, while the samples for the heat treatment $(n=3)$ were randomly chosen from the other 3 batches (see SOM, Section S3, Fig S3). The portions for each individual heat treatment were approximately $250 \mathrm{~g}$ mushrooms.

\subsection{Heat treatment}

The heat treatments are listed in Table 1 . All of the heat treatments were performed without adding any other ingredient. The fish were treated in an oven with and without aluminum foil wrapped around the trout fillet, imitating the procedure often performed in households. Freshly squeezed lemon juice was used to adjust the $\mathrm{pH}$ in sunflower oil, trout, and mushrooms. To each portion of sunflower oil, 2 drops of lemon juice were added to obtain a $\mathrm{pH}$ of 4.5 , whereas 5 drops of lemon juice were added to obtain a $\mathrm{pH}$ of 2.5. To each portion 
of boiled trout and mushrooms, lemon juice was added until the $\mathrm{pH}$ reached 4.0 in the water that was used for the trout and 3.5 in the water that was used to boil the mushrooms.

Table 1 Specification of cooking methods.

\subsection{Weighing and homogenization}

All of the samples were weighed raw and 30 min after heat treatment. All of the raw and processed samples were homogenized in a kitchen blender (FP220, Kenwood, United Kingdom) for $20 \mathrm{sec}$ and weighed in plastic bags, and the oxygen was replaced by nitrogen before closing the bags. The samples were stored at maximum of $-20^{\circ} \mathrm{C}$ until analysis, which took place within one month.

\subsection{Design}

Each heat treatment was performed three times independently of each other; e.g., three samples of steam-cooked fish were heated at three different times, whereas the analytical results represent a single determination of vitamin $\mathrm{D}$ metabolites.

\subsection{Cooking facilities}

The samples were baked in a Siemens stove (HL T650, Germany), cooked on a Bosch induction cooktop (PIE775N14E, Germany), and heated in a Panasonic microwave stove (NN E252W, Japan, $1200 \mathrm{~W}$ ). Pan-frying was conducted in a pan (Aldente Palermo, Teflon Platinum coating, diameter $=180 \mathrm{~mm}$ ). Furthermore, ordinary household cooking equipment, such as pots, baking trays, and sieves, were used for different kinds of heat treatments.

\subsection{Temperature and $\mathrm{pH}$ measurements}

The temperature in the oven during heating and the temperature in the middle of the samples were measured by a digital thermometer (Testo 735-2, Testo AG, Lenzkirch, Germany), 
whereas the final temperatures were measured by an analogue thermometer. The $\mathrm{pH}$ of the solution with added lemon juice was measured with a $\mathrm{pH}$ meter (PHM220, Radiometer analytical, France).

\subsection{Analytical method}

\subsubsection{Vitamin D}

For the quantification of vitamin $\mathrm{D}_{3}$ and vitamin $\mathrm{D}_{2}$ in sunflower oil, a previously described LC-ESI-MS/MS method for vitamin $\mathrm{D}_{3}$ and 25-hydroxyvitamin $\mathrm{D}_{3}$ in pork (Burild et al., 2014a; Burild et al., 2014b) was modified to include quantification of vitamin $\mathrm{D}_{2}$. Standards of vitamin $\mathrm{D}_{3}$ and vitamin $\mathrm{D}_{2}$ were obtained from Sigma-Aldrich (Steinheim, Germany), whereas the deuterated internal standard $26,26,26,27,27,27-d 6$-vitamin $\mathrm{D}_{3}\left(d 6-\mathrm{D}_{3}\right)$, was from Chemaphor Inc. (Ottawa, Canada). Prior to the extraction of $1 \mathrm{~g}$ oil, the deuterated internal standard listed above was added to the samples for analyses of vitamin $\mathrm{D}_{3}$ and vitamin $\mathrm{D}_{2}$. In short, sunflower-oil samples were saponified with ethanolic potassium hydroxide overnight at room temperature. The unsaponifiable matter was extracted by liquid/liquid extraction, cleaned-up by a silica solid-phase extraction (SPE), and derivatized with 4-phenyl-1,2,4triazole-3,5-dione (PTAD; Sigma-Aldrich, Steinheim, Germany) prior to the identification and quantification of vitamin $\mathrm{D}_{3}$ and vitamin $\mathrm{D}_{2}$ by a triple quadrupole MS detector. The equipment was from Agilent (LC 1200 and MS 6470 series Triple Quad MS, Agilent Technologies, Santa Clara, CA).

For analyses of fish and mushrooms, a HPLC-UV/PDA method was applied (Jakobsen et al. 2007; Kristensen et al., 2012). In short, vitamin $D_{2}$ and vitamin $D_{3}$ were added as internal standards to $1 \mathrm{~g}$ of fish and $10 \mathrm{~g}$ of mushrooms, respectively. The saponification, the liquidliquid extraction, and the SPE were similar as for sunflower oil. Furthermore, a normal-phase semi-preparative HPLC steps were included before the final separation, detection, and 
quantification, which was done by reverse-phase chromatography coupled to a photo-diode array detector (Alliance 2695; UV-detector 2487; PDA-detector 2996, Waters, Milford, MA).

The accuracy of the methods was secured by obtaining approved results i.e. within limits for the certified reference materials (Milk powder, CRM421, IRMM, Geel, Belgium) and a zscore $<1$ for proficiency testing materials (Milk Powder, FAPAS 2184, FAPAS, York, United Kingdom). Furthermore, the recovery of added $\mathrm{D}_{3}$ was $99.4 \pm 6.6 \%(\mathrm{n}=3)$ and $97.2 \pm 4.3 \%(\mathrm{n}=3)$ for UV/DAD and LC-MS/MS, respectively, and added $\mathrm{D}_{2}$ at $99.7 \pm 2.9 \%(\mathrm{n}=3)$ and $98.7 \pm 6.2 \%$ $(\mathrm{n}=10)$ for UV/DAD and LC-MS/MS, respectively. The consistency and precision of the methods during the studies were checked by analysis of control-salmon and controlmushrooms house-reference materials. In control-salmon, $15.4 \pm 0.2 \mu \mathrm{g}$ of vitamin $\mathrm{D}_{3} / 100 \mathrm{~g}$ was determined using the HPLC-UV/DAD method $(n=8)$, which was similar to the value obtained by the LC-MS/MS method $(\mathrm{n}=18)\left(15.2 \pm 0.8 \mu \mathrm{g}\right.$ vitamin $\left.\mathrm{D}_{3} / 100 \mathrm{~g}\right)$. For the controlmushroom, the content of vitamin $\mathrm{D}_{2}$ determined by HPLC-UV/DAD and LC-MS/MS was $16.8 \pm 1.1 \mu \mathrm{g}$ vitamin $\mathrm{D}_{2} / 100 \mathrm{~g}(\mathrm{n}=10)$ and $17.0 \pm 1.0 \mu \mathrm{g}$ vitamin $\mathrm{D}_{2} / 100 \mathrm{~g}(\mathrm{n}=5)$, respectively. All of the analyses were conducted in a laboratory that was accredited to perform the analyses according to ISO17025 (ISO, 2005).

\subsubsection{Weight loss and true retention}

The samples were weighed before and after heat treatment to calculate the percentage of weight loss; see Equation 1. Furthermore, weight data were combined with the amount of vitamin $\mathrm{D}$ in the raw samples and the amount of vitamin $\mathrm{D}$ in the heat-treated samples to calculate the true retention. The true retention calculation is exemplified by vitamin $D_{3}$ in equation 2 (Murphy et al., 1975). 
$\%$ Weight loss $=\left(\frac{\text { weight of sample before cooking-weight of sample after cooking }}{\text { weight of sample before cooking }}\right) * 100[1]$

$\%$ True retention $=\left(\frac{\mu g \text { vit D3 per } 100 \text { gram of cooked food } * \text { amount of cooked food }}{\mu g \text { vit D3 per } 100 \text { gram of raw food } * \text { amount of raw food }}\right) * 100$ [2]

\subsubsection{Statistical analysis}

The data for the retention of vitamin D in sunflower oil, fish, and mushrooms were statistically evaluated using JMP ${ }^{\circledR}$ Statistical Discovery software version 13.0 (SAS Institute Inc. Cary, NC, USA). A t-test was used to evaluate if the retention differed from $100 \%$, whereas a one-way ANOVA was used to test the retention of vitamin D in food after different cooking methods. The Tukey-Kramer test was used to examine the differences between the heating procedures and to compare different cooking methods. A p-value $\leq 0.05$ was classified as a significant difference. All of the results are given as mean \pm SD.

\section{Results}

The vitamin D contents found in the raw samples of sunflower oil, fish, and mushrooms are shown in Table 2.

Table 2 Content of vitamin D metabolites in raw samples.

Table 3 Sunflower oil - true retention of vitamin $D_{3}$ and vitamin $D_{2}$.

In rainbow trout, the vitamin $D_{3}$ content found in the raw samples was $7.5 \pm 1.7 \mu \mathrm{g} / 100 \mathrm{~g}$, whereas the weight loss ranged from 13-19\%. The final temperature in the inner parts of the cooked fish fillets was measured to be $69 \pm 3^{\circ} \mathrm{C}$. The temperature, time, and true retention results are shown in Table 4. 
Table 4 Rainbow trout (Oncorhynchus mykiss) - true retention of vitamin $\mathrm{D}_{3}$ and weight loss of raw and cooked samples.

The vitamin $\mathrm{D}_{2}$ content was $19.1 \pm 2.4 \mu \mathrm{g} / 100 \mathrm{~g}$ raw mushrooms. The weight loss ranged from $24-49 \%$. The temperature, time, true retention, and weight loss are shown in Table 5.

Table 5 Mushrooms - true retention of vitamin $\mathrm{D}_{2}$ and weight loss.

\section{Discussion}

There are limited dietary sources of vitamin D and information on its stability during processing and storage is scarce. The stability of vitamins depends on various conditions such as temperature, oxygen, light, moisture, $\mathrm{pH}$, and duration of heat treatment; this information is limited in the case of vitamin D metabolites (Lešková et al., 2006). Essential for retention studies is the application of a validated analytical method with an appropriate accuracy and precision, which includes the use of internal standard in vitamin D method. In our study the methods were run with an inter-day precision $<7 \%$. Furthermore, in our design we included appropriate control of the temperature used. Upreti, Mistry, \& Warthesen (2002) examined the stability of vitamin $\mathrm{D}_{3}$ in fortified cheese stored at room temperature and in a refrigerator (4$6^{\circ} \mathrm{C}$ ) and reported no losses during 9 months of storage. Furthermore, Kaushik, Sachdeva, \& Arora (2014) found statistically insignificant losses of vitamin $\mathrm{D}_{2}$ in fortified milk during pasteurization, boiling, and sterilization. However, the retention of vitamin D in different foods has been investigated and several contradictory results have been reported; the studies have shown that the retention of vitamin D varies between different foodstuffs and cooking methods. Bhuiyan et al. (1993) reported very modest loss of vitamin D in smoked Atlantic mackerel. Mattila et al. (1999) investigated the vitamin D retention in fish, eggs, and wild mushrooms following cooking and storage. They reported relatively high vitamin $\mathrm{D}_{3}$ retention in baked fish (78-104\%) and vitamin $\mathrm{D}_{2}$ retention in pan-fried wild mushrooms (80-100\%). 
We found no differences between the retention of vitamin $D_{3}$ and vitamin $D_{2}$ in spiked sunflower oil during various heat treatments. Although there was no significant difference, vitamin $\mathrm{D}_{2}$ tended to have a slightly higher retention than vitamin $\mathrm{D}_{3}$. A similar trend has been previously observed during the processing of pure substances of vitamin $\mathrm{D}_{3}$ and vitamin $\mathrm{D}_{2}$ (Grady \& Thakker, 1980) and vitamin $\mathrm{D}_{3}$ and vitamin $\mathrm{D}_{2}$ added to bread (Jakobsen \& Knuthsen, 2014). Furthermore, the highest baking temperature resulted in the lowest retention (Jakobsen \& Knuthsen, 2014), which was also the case in vitamin-D-spiked sunflower oil.

The retention of vitamin D3 in fish was not significantly different from 100\%, except when pan-frying was used as a cooking method. The retention ranged from $85-93 \%$, which was in accordance with the observation by Mattila et al. (1999), who did not find a significantly different loss from $100 \%$ for fish covered with foil and treated for $20 \mathrm{~min}$ in an oven at 172 $200^{\circ} \mathrm{C}$. Oven-cooking at a lower temperature, such as $110^{\circ} \mathrm{C}$ for $30 \mathrm{~min}$, resulted in no loss of vitamin $\mathrm{D}_{3}$, even though the final temperature in the fish was similar to fish cooked at $210^{\circ} \mathrm{C}$. Covering the fish with foil did not result in any difference in retention from fish treated in an oven without foil.

The retention of heat-treated mushrooms was $62-88 \%$, for which pan-frying on a strong fire, and baking in the oven at both low temperature $\left(70^{\circ} \mathrm{C}\right)$ and high temperature $\left(200^{\circ} \mathrm{C}\right)$ were significantly different from $100 \%$. The retention of vitamin $\mathrm{D}_{2}$ in mushrooms was significantly lower for samples that were boiled in water or baked in the oven $\left(200^{\circ} \mathrm{C}\right)$, which showed retention of $62-67 \%$, compared with the highest retention of $88 \%$ for mushrooms panfried at a low temperature. Mattila et al. (1999) investigated pan-frying of two types of wild mushrooms for 5 min and found retention of $80-82 \%$ for one species (C. Cibarius) and 97$100 \%$ for another species (C. Tubaeformis). In our investigation, the vitamin $\mathrm{D}_{2}$ bio-fortified button mushrooms that were pan-fried for $5 \mathrm{~min}$ at a high temperature showed a similar retention as $C$. Cibarius, i.e., $81 \pm 1 \%(\mathrm{n}=3)$. 
The heat treatment of the mushrooms samples was generally longer than the heat treatment of the fish samples, which could cause a lower retention of vitamin D. The duration of the heating procedures performed on the fish samples ranged from 2 min in microwave cooking to $30 \mathrm{~min}$ in the oven, whereas the mushrooms samples were heated for longer: $5 \mathrm{~min}$ of panfrying to $90 \mathrm{~min}$ in the oven in order to simulate normal cooking procedure. As fish are very often a source of unsafe food consumption caused by fast growth of bacteria, the final temperature in the inner parts of the fish was measured to ensure that the final temperature reached $69 \pm 3^{\circ} \mathrm{C}$. This temperature is high enough for safe consumption according to Davidson (2014), who reported that fish is cooked when its innermost parts have reached a temperature of approximately $63^{\circ} \mathrm{C}$.

In one of our previous studies, the retention of vitamin D in rye bread was determined to be lower than in white bread (Jakobsen \& Knuthsen, 2014). The investigation of the effect of pH between 4.0-7.1 in rye bread dough adjusted by adding hydrochloric acid showed that acidic environment did not significantly affect the retention of $71-75 \%$ (Jakobsen, unpublished). In the current study, we investigated the effect of different $\mathrm{pH}$ adjusted by adding lemon juice in sunflower oil at room temperature, and in oven-treated fish and boiled mushrooms. An acidic environment at room temperature had an insignificant effect on the vitamin D retention in sunflower oil. The boiling of fish and mushrooms samples resulted in the lowest retention rates out of all the cooking methods normally used in households. Boiling in an acidic environment, $\mathrm{pH} 4.0$ for fish and $\mathrm{pH} 3.5$ for mushrooms resulted in a higher retention than boiling in neutral water. In both types of samples, the vitamin D retention of samples that were cooked in a neutral environment was approximately $20 \%$ lower than the vitamin D retention in samples cooked in an acidic environment. Thus, the addition of lemon juice preserved vitamin $\mathrm{D}$ in fish and mushrooms during cooking, which could be owing to the antioxidant properties of ascorbic acid that was present in the acidic solution (Bendich et al., 
1986; Hajimahmoodi et al., 2012). These results indicate that the retention of vitamin D is improved by adding lemon juice prior to the heat treatment.

To our knowledge, this is the first study that examined the retention of the two main vitamin D metabolites spiked in a food based medium such as sunflower oil, and tested the effect of lemon juice on the retention of vitamin D during the household cooking. We used a highly accurate LC-MS/MS method. Furthermore, the experimental design took into consideration the differences in the distribution of the vitamin D in the fish. Analyzing the counterpart of the processed fish fillet enabled more reliable examination of the retention, since the assumption was that the content of the vitamin D is the same in the both parts separated by the spine.

A limitation of our study is the omission of the investigation of 25 -hydroxyvitamin $\mathrm{D}_{3}$. However, the content of 25-hydroxyvitamin $D_{3}$ in the trout was shown to be $0.09 \mu \mathrm{g} / 100 \mathrm{~g}$ in another study (Jakobsen \& Smith, 2017). This content was close to the limit of quantification for the method, which we do not find appropriate for a retention study. Furthermore, Jakobsen and Knuthsen (2014) examined the retention of vitamin $\mathrm{D}_{3}$ and 25-hydroxyvitamin $\mathrm{D}_{3}$ during three different cooking methods in eggs and no difference in retention was found.

The results obtained for fish indicate that no correction of vitamin D should be included for the calculation of dietary intake. In contrast, the vitamin D retention in household-cooked biofortified mushrooms should be regarded as different from 100\%. Even though we found a significant difference between the cooking methods, an average retention of $75 \%$ should be used to calculate the dietary intake. Mushroom soups prepared from vitamin $\mathrm{D}_{2}$ enriched mushrooms has been shown to be an excellent source of vitamin $\mathrm{D}_{2}$ which had equivalent bioavailability as a vitamin $\mathrm{D}_{2}$ supplement (Urbain et al., 2011). A portion of soup prepared from $100 \mathrm{~g}$ of vitamin D enriched mushroom with a content of $10 \mu \mathrm{g} / 100 \mathrm{~g}$ (legal for the EU- 
market) would provide $50-75 \%$ of the recommended daily intake, while a portion size of 200 $\mathrm{g}$ of fish would provide around $100 \%$ of the recommended daily intake. In summary, the dietary intake of vitamin D plays an enormous role in the prevention of its deficiency in humans, and meals composed of fish and vitamin D enriched mushrooms are good sources to ensure the recommended daily intake.

\section{Conclusion}

The retention of vitamin D in sunflower oil, fish, and mushrooms was determined after household cooking. No significant difference was found between the retention of vitamin- $\mathrm{D}_{3^{-}}$ and vitamin- $\mathrm{D}_{2}$-spiked sunflower oil. The true retention of vitamin $\mathrm{D}_{3}$ in fish was not significantly different from $100 \%$, except after pan-frying, with true retention rates ranging from $85-93 \%$. In mushrooms, the retention of vitamin $\mathrm{D}_{2}$ was significantly lower than $100 \%$ after pan-frying at high temperature and baking in the oven, with retention rates ranging from $62-88 \%$. In fish and mushrooms, the same trend was observed: the use of higher temperatures had a negative effect on vitamin D retention, whereas a lower acidity caused by the addition of lemon juice increased the retention of vitamin D.

Cooking may cause a significant loss of vitamin D, but the degree of loss depends on the combination of foodstuffs and the heating process. Based on the results in this study, we recommend that the retention of vitamin $\mathrm{D}_{3}$ in fish and vitamin $\mathrm{D}_{2}$ in bio-fortified mushrooms should be estimated at $100 \%$ and $75 \%$, respectively.

\section{Acknowledgment}

JJ designed the study in mushrooms, and JJ and PL designed the study in sunflower oil and fish. PL conducted the sampling and analyses of sunflower oil and fish samples. The authors are grateful for the assistance from Martin Lund-Larsen in conducting the study in mushrooms, and from Heidi Jahn for skillful technical assistance with the analyses of vitamin 
D. PL made the data analysis and wrote the manuscript, JJ reviewed and approved the final version of the manuscript. This research did not receive any specific grant from funding agencies in the public, commercial, or not-for-profit sectors. None of the authors had personal or financial conflicts of interest. 


\section{References}

Bendich, A., Machlin, L. J., Scandurra, O., Burton, G. W., \& Wayner, D. D. M. (1986). The antioxidant role of vitamin C. Advances in Free Radical Biology \& Medicine, 2(2), 419 444. http://doi.org/10.1016/S8755-9668(86)80021-7

Bhuiyan, A. K. M., Ratnayake, W. M. N., \& Ackman, R. G. (1993). (1993). Nutritional composition of raw and smoked Atlantic mackerel (Scomber scombrus): Oil- and watersoluble vitamins. Journal of Food Composition and Analysis, 6, 172-184. http://doi.org/ 10.1006/jfca.1993.1019

Bikle, D. D. (2014). Vitamin D metabolism, mechanism of action, and clinical applications. Chemistry \& Biology, 21(3), 319-329. http://doi.org/10.1016/j.chembiol.2013.12.016

Burild, A., Frandsen, H. L., \& Jakobsen, J. (2014a). Simultaneous quantification of vitamin $\mathrm{D}_{3}, 25$-hydroxyvitamin $\mathrm{D}_{3}$ and 24,25-dihydroxyvitamin $\mathrm{D}_{3}$ in human serum by LCMS/MS. Scandinavian Journal of Clinical and Laboratory Investigation, 74(5), 418423. http://doi.org/10.3109/00365513.2014.900694

Burild, A., Frandsen, H. L., Poulsen, M., \& Jakobsen, J. (2014b). Quantification of physiological levels of vitamin $\mathrm{D}_{3}$ and 25-hydroxyvitamin $\mathrm{D}_{3}$ in porcine fat and liver in subgram sample sizes. Journal of Separation Science, 37(19), 2659-2663. http://doi.org/10.1002/jssc.201400548

Cashman, K D., Dowling, K. G., Škrabáková, Z., Gonzalez-Gross, M., Valtueña, J., De Henauw, S., Moreno, L., Damsgaard, C. T., Michaelsen, K. F., Mølgaard, C., Jorde, R., Grimnes, G., Moschonis, G., Mavrogianni, C., Manios, Y., Thamm, M., Mensink, G. B. M., Rabenberg, M., Busch, M A., Cox, L., Meadows, S., Goldberg, G., Prentice, A., Dekker, J. M., Nijpels, G., Pilz, S., Swart, K. M., van Schoor, N. M., Lips, P., 
Eiriksdottir, G., Gudnason, V., Cotch, M. F., Koskinen, S., Lamberg-Allardt, C., Durazo-Arvizu, R. A., Sempos, C. T., \& Kiely, M. (2016). Vitamin D deficiency in Europe: pandemic? American Journal of Clinical Nutrition, 103(4), 1033-1044. http://doi.org/10.3945/ajcn.115.120873

Daly, R. M., Gagnon, C., Lu, Z. X., Magliano, D. J., Dunstan, D. W., Sikaris, K. A., Zimmet, P. Z., Ebeling, P. R., \& Shaw, J. E. (2012). Prevalence of vitamin D deficiency and its determinants in Australian adults aged 25 years and older: A national, population-based study. Clinical Endocrinology, 77(1), 26-35. http://doi.org/10.1111/j.13652265.2011.04320

Davidson, A., Jaine, T. (2014). The Oxford companion to food. ( $3^{\text {rd }}$ ed.). Oxford: Oxford University Press. http://doi.org/10.1093/acref/9780199677337.001.0001

Grady, L.T. \& Thakker, K. D. (1980). Stability of solid drugs: Degradation of ergocalciferol (vitamin $\mathrm{D}_{2}$ ) and cholecalciferol (vitamin $\mathrm{D}_{3}$ ) at high humidities and elevated temperatures. Journal of Pharmaceutical Sciences, 69(9), 1099-1102. http://doi.org/ $10.1002 / j p s .2600690932$

Hajimahmoodi, M., Aliabadipoor, M., Moghaddam, G., Sadeghi, N., Oveisi, M. R., \& Jannat, B. (2012). Evaluation of in vitro antioxidant activities of lemon juice for safety assessment. American Journal of Food Technology, 7(11), 708-714. http://doi.org/10.3923/ajft.2012.708.714

Institute of Medicine. (2011). Dietary reference intakes for calcium and vitamin D. Washington DC: The National Academies Press. https://doi.org/10.17226/13050

Jakobsen, J., \& Knuthsen, P. (2014). Stability of vitamin D in foodstuffs during cooking. Food Chemistry, 148, 170-175. http://doi.org/10.1016/j.foodchem.2013.10.043 
Jakobsen, J., Krogh Jensen, S., Hymøller, L., Wreford Andersen, E., Kaas, P., Burild, A., \& Jäpelt, R. B. (2015). Artificial ultraviolet B light exposure increases vitamin D levels in cow plasma and milk. Journal of Dairy Science, 98, 6492-6498. https://doi.org/10.3168/jds.2014-9277

Jakobsen, J., Maribo, H., Bysted, A., Sommer, H. M., \& Hels, O. (2007). 25-Hydroxyvitamin D3 affects vitamin D status similar to vitamin D3 in pigs - but the meat produced has a lower content of vitamin D. British Journal of Nutrition, 98(5), 908-913. http://doi.org/10.1017/S0007114507756933

Jakobsen, J., \& Smith, C. (2017). Farmed salmon and farmed rainbow trout - excellent sources of vitamin D? Fisheries and Aquaculture Journal, 8(2).1-5. http://doi.org/10.4172/2150-3508.1000204

Kaushik, R., Sachdeva, B., \& Arora, S. (2014). Vitamin $\mathrm{D}_{2}$ stability in milk during processing, packaging and storage. LWT - Food Science and Technology, 56(2), 421426. http://doi.org/10.1016/j.lwt.2013.11.029

Keegan, R. J. H., Lu, Z., Bogusz, J. M., Williams, J. E., \& Holick, M. F. (2013). Photobiology of vitamin D in mushrooms and its bioavailability in humans. Dermato-Endocrinology, 5(1), 165-176. http://doi.org/10.4161/derm.23321

Koyyalamudi, S. R., Jeong, S. C., Song, C. H., Cho, K. Y., \& Pang, G. (2009). Vitamin D 2 formation and bioavailability from Agaricus bisporus button mushrooms treated with ultraviolet irradiation. Journal of Agricultural and Food Chemistry, 57(8), 3351-3355. http://doi.org/10.1021/jf803908q

Kristensen, H. L., Rosenqvist, E., \& Jakobsen, J. (2012). Increase of vitamin D $_{2}$ by UV-B exposure during the growth phase of white button mushroom (Agaricus bisporus). Food and Nutrition Research, 56, 1-7. http://doi.org/10.3402/fnr.v56i0.7114 
Lešková, E., Kubíková, J., Kováčiková, E., Košická, M., Porubská, J., \& Holčíková, K. (2006). Vitamin losses: Retention during heat treatment and continual changes expressed by mathematical models. Journal of Food Composition and Analysis, 19(4), 252-276. http://doi.org/10.1016/j.jfca.2005.04.014

Mattila, P., Ronkainen, R., Lehikoinen, K., \& Piironen, V. (1999). Effect of household cooking on the vitamin D content in fish, eggs, and wild mushrooms. Journal of Food Composition and Analysis, 12(3), 153-160. http://doi.org/10.1006/jfca.1999.0828

Murphy, E. W., Criner, P. E., \& Gray, B. C. (1975). Comparisons of methods for calculating retentions of nutrients in cooked foods. Journal of Agricultural and Food Chemistry, 23(6), 1153-1157. http://doi.org/10.1021/jf60202a021

Nordic Nutrient Recommendation (2014). Nordic Nutrition Recommendations 2012. Nordic Council of Ministers. 5(11), 1. http://dx.doi.org/10.6027/Nord2014-002. Retrieved on $19^{\text {th }}$ of June, 2017.

O’Mahony, P. (2016, February 26). Application for the approval of UV-treated mushrooms with increased vitamin D level under the novel food Regulation (EC) No. 258/97. [Authorization letter] Retrived from https://ec.europa.eu/food/sites/food/files/safety/docs/novelfood_authorisation_2016_auth-letter_uv-mushrooms_en.pdf

O'Mahony, P. (2017, August 28). Application for the approval of UV-treated mushrooms (Agaricus bisporus) as a novel food under the novel food Regulation (EC) No. 258/97. [Authorization letter] Retrived from https://ec.europa.eu/food/sites/food/files/safety/docs/novelfood_authorisation_2017_auth-letter_uv-mushrooms_en.pdf

Pedersen, A. N., Christensen, T., Matthiessen, J., Knudsen, V. K., Rosenlund-Sørensen, M., 
Biltoft-Jensen, A., Hinsch, H-J., Ygil, K. H., Kørup, K., Saxholt, E., Trolle, E., Søndergaard, A.B., Fagt, S. (2015). Danskernes kostvaner 2011-2013. Main result. DTU Fødevareinstituttet, Mørkhøj Bygade 19, DK-2860 Søborg, Denmark. ISBN: 978-8793109-39-1

Upreti, P., Mistry, V. V, \& Warthesen, J. J. (2002). Estimation and fortification of vitamin $\mathrm{D}_{3}$ in pasteurized process cheese. Journal of Dairy Science, 85(12), 3173-3181. http://doi.org/10.3168/jds.S0022-0302(02)74405-6

Urbain, P., Singler, F., Ihorst, G., Biesalski, H.-K., \& Bertz, H. (2011). Bioavailability of vitamin $\mathrm{D}_{2}$ from UV-B-irradiated button mushrooms in healthy adults deficient in serum 25-hydroxyvitamin D: a randomized controlled trial. European Journal of Clinical Nutrition, 65(8), 965-971. http://doi.org/10.1038/ejcn.2011.53

USDA National Nutrient Database for Standard Reference Release 28 (2016). Retrived from https://ndb.nal.usda.gov on $30^{\text {th }}$ of March, 2017.

USDA Table of Nutrient Retention Factors, Release 6 (2007). Retrieved from https://www.ars.usda.gov on $19^{\text {th }}$ of April, 2017.

Wacker, M., \& Holick, M. F. (2013). Sunlight and Vitamin D. Dermato-Endocrinology, 5(1), 51-108. http://doi.org/10.4161/derm.24494

Webb, A. R. (2006). Who, what, where and when-influences on cutaneous vitamin D synthesis. Progress in Biophysics and Molecular Biology, 92(1), 17-25. http://doi.org/10.1016/j.pbiomolbio.2006.02.004 

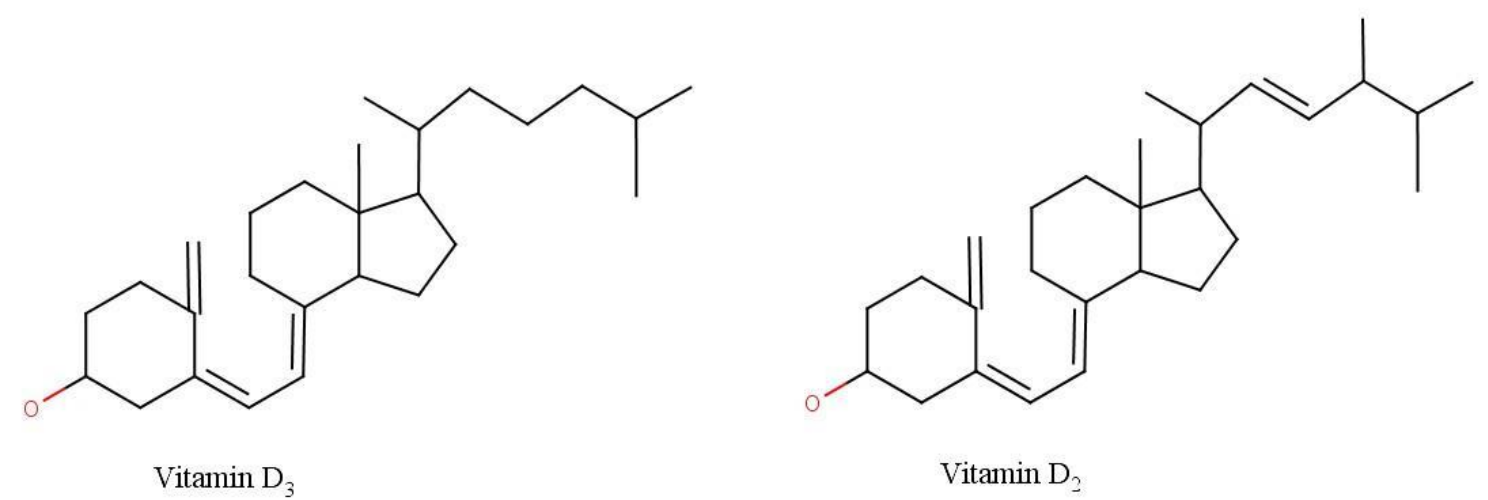

Vitamin $\mathrm{D}_{3}$ 
Table 1 Specification of cooking procedures.

\begin{tabular}{clcc}
\hline Food item & \multicolumn{1}{c}{ Treatment } & $\begin{array}{c}\text { Time } \\
(\mathbf{m i n})\end{array}$ & $\begin{array}{c}\text { Temperature } \\
\left({ }^{\circ} \mathbf{C}\right)\end{array}$ \\
\hline & Air & 180 & $20 \pm 1$ \\
Sunflower oil & Oven (Low temperature, Long time) & 30 & $110 \pm 10$ \\
fortified with & Oven (High temperature, Short time) & 10 & $210 \pm 10$ \\
vitamin $\mathbf{D}_{\mathbf{3}}$ and & Pan-frying, high level & 1 & n.m. \\
vitamin $\mathbf{D}_{\mathbf{2}}$ & Microwave, high power & 1 & n.m. \\
& Lemon juice (pH 4.5) & 10 & $20 \pm 1$ \\
& Lemon juice (pH 2.5) & 10 & $20 \pm 1$ \\
\hline & Boiling & 8 & $90 \pm 2$ \\
& Boiling, lemon juice (pH 4.0) & 8 & $90 \pm 2$ \\
& Steam cooked & 6 & $87 \pm 3$ \\
Rainbow trout & Microwave cooked & 2 & $\mathrm{n} . \mathrm{m}$. \\
& Pan-fried & 8 & $\mathrm{n} . \mathrm{m}$. \\
& Baked, oven (uncovered) & 30 & $110 \pm 9$ \\
& Baked, oven (uncovered) & 10 & $210 \pm 12$ \\
& Baked, oven (covered) & 15 & $190 \pm 14$ \\
\hline & Boiling & 20 & $90 \pm 2$ \\
& Boiling, lemon juice (pH 3.5) & 20 & $90 \pm 2$ \\
Mushrooms bio- & Pan-fried, high heat & 5 & $\mathrm{n} . \mathrm{m}$. \\
fortified with & Pan-fried, low heat & 20 & $\mathrm{n} . \mathrm{m}$. \\
vitamin $\mathbf{D}_{\mathbf{2}}$ & Baked, oven (uncovered) & 90 & $70 \pm 4$ \\
& Baked, oven (uncovered) & 20 & $200 \pm 9$ \\
\hline
\end{tabular}

n.m. = not measured 
Table 2 Content of vitamin D metabolites in raw samples.

\begin{tabular}{|c|c|c|c|}
\hline$\mu \mathrm{g} / 100 \mathrm{~g}$ raw sample & & & Sample number \\
\hline & Vitamin $D_{3}$ & Vitamin $D_{2}$ & \\
\hline Sunflower oil fortified with vitamin $D_{3}$ and vitamin $D_{2}$ & $14.5 \pm 0.6$ & $11.2 \pm 0.6$ & 3 \\
\hline Rainbow trout & $7.5 \pm 1.7$ & $<0.1$ & ? \\
\hline Mushrooms bio-fortified with vitamin $\mathrm{D}_{2}$ & $<0.01$ & $19.2 \pm 2.4$ & 6 \\
\hline
\end{tabular}


Table 3 Sunflower oil - true retention of vitamin $D_{3}$ and vitamin $D_{2}$.

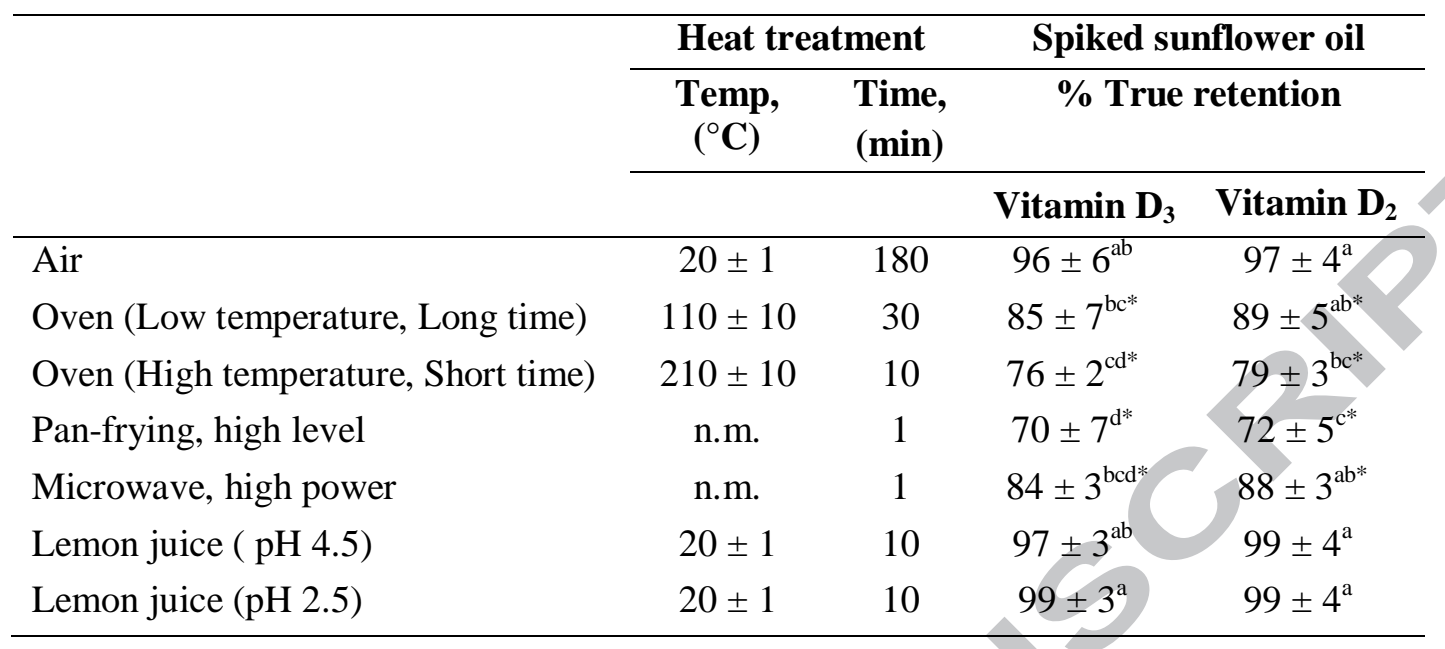

Number of repetitions for each treatment: $n=3$. The different letters in a column indicate significant differences $(\mathrm{p} \leq 0.05)$. A star $\left(^{*}\right)$ indicates a retention significantly different from $100 \%(\mathrm{p} \leq 0.05) . \mathrm{n} \cdot \mathrm{m} .=$ not measured 
Table 4 Rainbow trout (Oncorhynchus mykiss) - true retention of vitamin $\mathrm{D}_{3}$ and weight loss of cooked samples

\begin{tabular}{|c|c|c|c|c|c|}
\hline & \multicolumn{2}{|c|}{ Heat treatment } & \multicolumn{3}{|c|}{ Fish (Rainbow trout) } \\
\hline & \multirow{2}{*}{$\begin{array}{c}\text { Temp, } \\
\left({ }^{\circ} \mathrm{C}\right)\end{array}$} & \multirow{2}{*}{$\begin{array}{l}\text { Time, } \\
\text { (min) }\end{array}$} & \multirow{2}{*}{$\begin{array}{c}\text { Final T } \\
\left({ }^{\circ} \mathbf{C}\right)\end{array}$} & True retention & Weight loss \\
\hline & & & & $\%$ Vitamin $D_{3}$ & $\%$ \\
\hline Boiling & $90 \pm 2$ & 8 & $68 \pm 2$ & $87 \pm 16^{\mathrm{ab}}$ & $14 \pm 1.3^{\mathrm{ab}}$ \\
\hline Boiling, lemon juice & $90 \pm 2$ & 8 & $68 \pm 3$ & $102 \pm 9^{a b}$ & $14 \pm 1.1^{\mathrm{ab}}$ \\
\hline Steam cooked & $87 \pm 3$ & 6 & $67 \pm 2$ & $97 \pm 5^{\mathrm{ab}}$ & $\pm 2.6^{\mathrm{b}}$ \\
\hline Microwave cooked & n.m. & 2 & $69 \pm 3$ & $101 \pm 1^{\mathrm{ab}}$ & $19 \pm 0.8^{\mathrm{a}}$ \\
\hline Pan-fried & n.m. & 8 & $65 \pm 1$ & $85 \pm 6^{b^{*}}$ & $18 \pm 2.9^{\mathrm{ab}}$ \\
\hline Baked, oven (uncovered) & $110 \pm 9$ & 30 & $70 \pm 2$ & $114 \pm 13^{\mathrm{a}}$ & $15 \pm 0.6^{\mathrm{ab}}$ \\
\hline Baked, oven (uncovered) & $210 \pm 12$ & 10 & $65 \pm 2$ & $87 \pm 14^{\mathrm{ab}}$ & $17 \pm 2.0^{\mathrm{ab}}$ \\
\hline Baked, oven (covered) & $190 \pm 14$ & 15 & $80 \pm 2$ & $93 \pm 8^{\mathrm{ab}}$ & $16 \pm 1.6^{\mathrm{ab}}$ \\
\hline
\end{tabular}

Number of repetitions for each treatment: $n=3$, i.e., for each cooking method 6 samples ( 3 raw and 3 cooked). The different letters in a column indicate significant differences $(p \leq 0.05)$. A star $(*)$ indicates a retention significantly different from $100 \%(\mathrm{p} \leq 0.05) . \mathrm{n} . \mathrm{m} .=$ not measured 
Table 5 Mushrooms - true retention of vitamin $\mathrm{D}_{2}$ and weight loss.

\begin{tabular}{|c|c|c|c|c|c|}
\hline & \multicolumn{2}{|c|}{ Heat treatment } & \multicolumn{3}{|c|}{ Vitamin $\mathrm{D}_{2}$ bio-fortified mushrooms } \\
\hline & \multirow{2}{*}{$\begin{array}{c}\text { Temp, } \\
\left({ }^{\circ} \mathrm{C}\right)\end{array}$} & \multirow{2}{*}{$\begin{array}{l}\text { Time, } \\
\text { (min) }\end{array}$} & \multirow{2}{*}{$\begin{array}{c}\text { Final T } \\
\left({ }^{\circ} \mathbf{C}\right)\end{array}$} & \multirow{2}{*}{$\begin{array}{l}\text { True retention } \\
\% \text { Vitamin } D_{2} \\
\end{array}$} & \multirow{2}{*}{$\frac{\text { Weight loss }}{\%}$} \\
\hline & & & & & \\
\hline Boiling & $90 \pm 2$ & 20 & n.m. & $62 \pm 14^{b}$ & $26 \pm 0.3^{\mathrm{a}}$ \\
\hline Boiling, lemon juice & $90 \pm 2$ & 20 & n.m. & $80 \pm 5^{\mathrm{ab}}$ & $24 \pm 0.3^{\mathrm{a}}$ \\
\hline Pan-fried, high heat & n.m. & 5 & n.m. & $81 \pm 1^{\mathrm{ab} *}$ & $27 \pm 0.2^{\mathrm{b}}$ \\
\hline Pan-fried, low heat & n.m. & 20 & n.m. & $88 \pm 9^{\mathrm{a}}$ & $35 \pm 0.6^{c}$ \\
\hline Baked, oven (uncovered) & $70 \pm 4$ & 90 & n.m. & $74 \pm 2^{\mathrm{ab}^{*}}$ & $49 \pm 0.9^{\mathrm{d}}$ \\
\hline Baked, oven (uncovered) & $200 \pm 9$ & 10 & n.m. & $67 \pm 3^{b^{*}}$ & $48 \pm 2^{\mathrm{d}}$ \\
\hline
\end{tabular}

Each cooking method was repeated 3 times, except for "Boiling" $n=2$. Six raw samples were analyzed. The different letters in a column indicate significant differences $(\mathrm{p} \leq 0.05)$. A star $(*)$ indicates a retention significantly different from $100 \%(\mathrm{p} \leq 0.05)$. n.m. $=$ not measured 


\section{Highlights}

- Household cooking methods affect the retention of vitamin D in oil, trout, and mushrooms

- Lower cooking temperature results in higher vitamin D retention

- No difference between the retention of vitamin $D_{3}$ and vitamin $D_{2}$ spiked in oil

- Lemon juice added to boiling water increases the retention of vitamin D 